\title{
Silte da Formação Guabirotuba estabilizado com resíduo da indústria da celulose e papel
}

\author{
Stabilized Guabirotuba Silt with waste from \\ cellulose and paper industry
}

Ronaldo Luis dos Santos Izzo ${ }^{1}$, Jair de Jesús Arrieta Baldovino ${ }^{1}$, Alexandre Erbs ${ }^{1}$, Danilo Lima ${ }^{1}$, Ölaf Graupmann ${ }^{1}$

\footnotetext{
${ }^{1}$ Laboratório de Geotecnia, LABGEO - PPGEC/Universidade Tecnológica Federal do Paraná (UTFPR), Rua Deputado Heitor Alencar Furtado, 5000, CEP: 81280-340, Curitiba, Paraná, PR, Brasil.

e-mail: izzo@utfpr.edu.br, yaderbal@hotmail.com, aleerbs@gmail.com, daslima83@gmail.com, eugraupmann@yahoo. com.br
}

\section{RESUMO}

A resistência à compressão simples, a resistência à tração por compressão diametral e o Índice de Suporte de Califórnia (CBR) foram sistematicamente pesquisados para analisar o desempenho de um solo siltoso da região metropolitana de Curitiba (Brasil) estabilizado com cinza da indústria da produção de papel e com cal dolomítica hidratada. Uma série de ensaios de compactação na energia Proctor normal foram realizados para calcular os parâmetros ótimos de compactação das misturas solo-cinza-cal: peso específico seco máximo $\left(\gamma_{\mathrm{d}-\max }\right)$ e teor de umidade ótimo $\left(\omega_{\mathrm{o}}\right)$. Foram adicionados e utilizados 4 teores de cinza de celulose $(5 \%, 10 \%, 15 \%$ e $20 \%$ em relação à massa seca do solo) e um teor fixo de cal (L) de $5 \%$ baseado no consumo inicial de cal modificado, estabelecido a partir da interpretação das medidas de $\mathrm{pH}$ realizadas em várias misturas solo-cinza-cal. Os resultados demonstram que existe um aumento no teor de umidade ótimo e uma diminuição no peso específico seco máximo das curvas de compactação com o aumento do teor de cinza de celulose. Por outro lado, os ensaios de compressão simples, tração por compressão diametral e CBR revelam que existe um acréscimo nos valores de resistência mecânica das misturas até um teor de cinza de 15\%. Em adição, a Espectroscopia por Dispersão de Energia (EDS) feita em uma mistura protótipo mostra que houve uma interação química entre o solo, a cal e as partículas menores da cinza de celulose. Finalmente, equações de dosagem que permitem estimar os valores da resistência das misturas foram desenvolvidas baseadas na relação semiempirica porosidade/cal $\left(\eta / L_{\mathrm{iv}}\right)$ tendo em consideração a massa específica e o volume dos materiais, além da energia de compactação.

Palavras-chave: Solo-cinza-cal, compressão simples, tração por compressão diametral, índice porosidade/cal.

\begin{abstract}
The unconfined compressive strength, the splitting tensile strength and the California Bearing Ratio (CBR) were systematically investigated to analyze the performance of a silt soil from the metropolitan region of Curitiba (Brazil) stabilized with cellulose ash and with hydrated dolomitic lime. A series of compaction tests on normal Proctor energy were performed to calculate the optimum compaction parameters of the soil- cellulose ash-lime mixtures: maximum dry unit weight $\left(\gamma_{\mathrm{d}}\right.$ $\left.{ }_{\max }\right)$ and optimum moisture content $\left(\omega_{\mathrm{o}}\right)$. Four percentages of cellulose ash $(5 \%, 10 \%, 15 \%$ and $20 \%$ in relation to the dry mass of the soil) were added and used, and a fixed content of lime (L) of $5 \%$ based on the modified initial consumption of lime and established from the interpretation of $\mathrm{pH}$ measurements performed on several soil-ash-lime mixtures. The results demonstrate that there is an increase in the optimum moisture content and a decrease in the maximum dry unit weight of the compaction curves with increasing the cellulose ash content. On the other hand, the tests of unconfined compression, splitting tensile and CBR show that there is an increase in the mechanical strength values of the blends up to an optimal content of $15 \%$. In addition, Energy Dispersion Spectroscopy (EDS) made in a prototype blend shows that there was a chemical interaction between soil, lime and the smallest particles of cellulose ash. Finally, dosing equations that allow estimation of the strength values of the blends were developed based on porosity/lime index $\left(\eta / L_{\mathrm{iv}}\right)$ considering the specific gravity and volume of the materials besides the compaction energy.
\end{abstract}

Keywords: Soil-celulose ash-lime, unconfined compressive strength, split tensile strength, porosity/lime index. 


\section{INTRODUÇÃO}

O alto custo empregado em obras rodoviárias e a necessidade de buscar uma vida útil satisfatória ao empreendimento leva a engenharia a sempre tentar melhorar e descobrir meios de aumentar a vida útil do material empregado. Outro fator que vem ganhando força é a destinação de materiais que não teriam utilidade, mas que, adicionados ao solo, melhoram suas características mecânicas, como por exemplo, a cal, o cimento, as cinzas volantes, os resíduos da construção e da demolição civil, dentre outros [1-3]. Com isto se amplia a gama de materiais disponíveis para utilização por engenheiros. Neste sentido, existem os materiais já costumeiramente utilizados para a estabilização do solo, como a cal e o cimento, dependendo da característica do substrato em questão, e surgem novas alternativas como as cinzas de celulose, que podem ser utilizadas considerando a disponibilidade do material na região do empreendimento.

É possível melhorar as características físicas, químicas e mecânicas de um dado solo através de sua estabilização, ou seja, aumentar sua resistência com o intuito de suportar as cargas que lhe serão aplicadas. Dentre as estabilizações conhecidas podemos citar a estabilização química que, dependendo do tipo de solo, pode funcionar melhorando sua resistência ao cisalhamento através de ligantes como o cimento e a cal, que se alocam no ponto de contato dos grãos [4]. A adição de cimento ao solo diminui a sua permeabilidade, ou seja, evita a entrada de água, evitando processos erosivos também conferindo ao solo uma maior rigidez, o que permite resistir a solicitações mais altas quando comparado ao mesmo solo "in natura". A utilização de cal para estabilização do solo é algo comum em obras rodoviárias. Com a adição de cal ao solo, observa-se a alteração do $\mathrm{pH}$, pois esta é alcalina, e com esta alteração química podem ser observadas reações de floculação e aglomeração em decorrência da troca iônica entre a cal e a argila presente no substrato [5].

A cal produz melhoria em diversas características do solo, como na diminuição da plasticidade e expansibilidade, na granulometria, na quantidade de finos e no índice de suporte. Conforme PUPPALA [6] a estabilização de solos com cal tem se revelado um método eficaz, ecológico e econômico, que permite o aproveitamento do mesmo no local onde a obra será implementada, ao invés de substituí-los por outros provenientes de outras localidades, o que evita despesas adicionais e impactos ambientais. Pode-se também utilizar cinzas para a estabilização do solo, neste caso, se cria um ambiente alcalino que permite a dissolução da sílica presente no solo e da alumina presente nas cinzas, o que resulta em uma pasta com propriedades colantes que proporciona melhoria nas características do solo e também uma destinação às cinzas resultantes de processos industriais e que muitas vezes não têm uma destinação específica [7-9].

A Formação Guabirotuba (FG) é a principal unidade geológica observada em Curitiba e região metropolitana, apresentando uma área de aproximadamente $3000 \mathrm{~km}^{2}$. É composta por sedimentos do Terciário médio ao superior, constituindo-se principalmente de argilas siltosas (esmectita) ou siltes argilosos e silitos esverdeados, com presença de areias arcosianas [10]. A instabilidade do solo em escavações da Formação Guabirotuba é frequentemente atribuída à expansibilidade da esmectita, tipicamente caracterizada como um material expansivo. Apesar de o clima presente colaborar para manter os solos da Bacia de Curitiba com um maior teor de umidade, o equilíbrio natural pode ser modificado pela ação antrópica. [11]. Tem-se como exemplo a remoção do solo superficial em serviços de terraplenagem, áreas de empréstimo, escavações ou cavas de fundações [10]. As argilas que compõem a Formação Guabirotuba são expansivas, retrativas e higroscópicas, atributos que lhes conferem uma alta erodibilidade. Nas condições em que se encontram na natureza, recobertas pelo solo residual, as argilas mantêm-se com sua umidade natural, não manifestando nenhuma instabilidade. Caso a camada de solo superficial venha a ser retirada, esta argila exposta perde água e se retrai, apresentando empastilhamento e trincas características [12]. Com a água da chuva, a argila se reidrata, expande e desagrega, formando um leito centimétrico por toda a superfície exposta de partículas finas e que, em função do escoamento superficial, é facilmente transportada, dando origem à erosão por escoamento concentrado [13]. Quanto maior for a declividade e extensão das encostas, maior será o escoamento concentrado. Quanto maior a energia das águas, maior será o transporte de partículas e mais acelerado será o processo de formação de sulcos e ravinas, que podem atingir grandes proporções [14].

Solos expansivos da FG tornam-se potencialmente instáveis quando sua umidade natural é inferior a $15 \%$, apresentando intensas sucções que se desenvolvem devido à presença de esmectita. O aumento das tensões efetivas provoca uma contração volumétrica intensa vencendo a rigidez que eventuais ligações entre partículas conferem ao material em seu estado natural. O comportamento estável que o solo apresenta para pequenas oscilações da umidade natural não se preserva em um processo de ressecamento [12]. Uma vez ressecado, se a água entra em contato com o terreno, este se desagrega, iniciando-se um processo erosivo [14]. Para resolver esta dificuldade, a literatura sugere principalmente a adição de cal. A cal é um aglomerante obtido pela calcinação em temperaturas entre $850^{\circ} \mathrm{C} \mathrm{e} 900^{\circ} \mathrm{C}$ de rochas calcárias constituídas por carbonato de cálcio e carbonato magnésio. O processo dá origem ao óxido de cálcio $(\mathrm{CaO})$ e cálcio-magnésio $(\mathrm{CaO}-\mathrm{MgO})$ também chamado de cal virgem. Essa cal virgem quando em contato com água, hidrata liberando grande quantidade de calor e resulta na cal hidratada $\left(\mathrm{Ca}(\mathrm{OH})_{2}\right)[15]$.

A adição de pequenas quantidades de cal tende a modificar as propriedades do solo, enquanto maiores quantidades poderão alterar suas propriedades. A primeira resposta da mistura solo-cal é a redução do índice de plasticidade e melho- 
ria na trabalhabilidade. A segunda é o ganho de resistência através da cimentação das partículas. Desta forma, a adição de cal é recomendada para a estabilização de solos coesivos, pois promove interação entre as partículas proporcionando modificações físico-químicas, o que aumenta sua estabilidade face à ação da água. A cal também promove uma melhoria significativa na textura e na estrutura do solo, diminuindo a plasticidade e aumentando os valores de resistência mecânica. Além disso, se verifica um aumento considerável da resistência a longo prazo. Por outro lado, o aumento de resistência na mistura solo-cal resulta na redução substancial do seu potencial de deformação [16].

De acordo com BEHAK [15], a adição de cal em solos argilosos altera suas propriedades físicas e mecânicas, resultando em melhorias nas resistências, no comportamento de tensão-deformação, na plasticidade, na estabilidade volumétrica, na trabalhabilidade e na condutividade hidráulica. Essas modificações dependem de diversos fatores, tais como tipo de solo, tipo e teor de cal, energia de compactação, tempo e condições de cura.

Quando adicionado cal a um solo fino em presença de água, ocorrem quatro reações químicas principais que são: a troca catiônica, a floculação-aglomeração, as reações pozolânicas e a carbonatação. A troca catiônica e a floculação-aglomeração iniciam imediatamente após a cal entrar em contato com a água, estas reações modificam as propriedades físicas do solo (plasticidade, textura, trabalhabilidade, estabilidade volumétrica), sem alteração considerável de resistência [5,6]. As reações pozolânicas e a carbonatação iniciam-se algumas semanas após a cal entrar em contato com a água e desenvolvem-se durante um longo período de tempo, da ordem de vários anos em alguns casos. As reações pozolânicas causam a formação de produtos cimentantes e são as responsáveis pelo aumento da resistência e da durabilidade das misturas solo-cal. A carbonatação é a reação não desejada, pois produz ligações fracas e prejudica o processo de estabilização [17].

As cinzas, quando em contato com a água, reagem quimicamente com hidróxidos alcalinos e alcalinos terrosos em temperatura ambiente para formar ou auxiliar na formação de compostos com propriedades cimentantes [18]. As partículas de solo juntamente com a cal e parte do dióxido de carbono presente na água, combinadas com a cinza, dão origem a reação de natureza pozolânica. A adição de materiais pozolânicos, tais como as cinzas, auxilia na produção de níveis de reação desejados com a cal. CONSOLI et al. [19], ao estudar um solo arenoso tratado com cinza volante e cal de carbureto (i.e. resíduo gerado da produção do gás acetileno), verificaram que os novos materiais constituídos pelas misturas entre o solo e os resíduos apresentaram desempenho bastante superior em termos de resistência ao cisalhamento e deformabilidade.

De acordo com NOLASCO et al. [20], a cada miligrama de celulose produzida são gerados 0,15 miligramas de resíduos de naturezas diversas. Da composição média dos resíduos da produção de celulose e papel, as cascas representam $24 \%$, a lama de cal $22 \%$, os lodos $17 \%$, dregs e grits $14 \%$ e as cinzas $11 \%$. Esses percentuais podem variar, uma vez que as cascas podem ser utilizadas em caldeiras para a geração de energia, resultando em maior quantidade de cinza gerada. Por outro lado, MARCON et al. [21] cita que a resistência à tração na compressão diametral conduz a menores valores que a resistência à tração na flexão. Os autores constataram também que o quociente entre a resistência à tração pela resistência à compressão simples (i.e. $\mathrm{q}_{\mathrm{t}} / \mathrm{q}_{\mathrm{u}}$ ) das misturas solo-cal estudadas, varia de $\mathrm{q}_{\mathrm{t}} / \mathrm{q}_{\mathrm{u}}=0,10$ a $\mathrm{q}_{\mathrm{t}} / \mathrm{q}_{\mathrm{u}}=0,15$, independentemente do tipo e/ou teor de cal.

Recentes estudos demostram a melhoria dos solos da Formação Guabirotuba usando diferentes estabilizantes. BALDOVINO et al. [5] estudaram a melhoria de um solo siltoso da FG estabilizado com cal hidratada usando 180 dias de cura apresentando uma melhora tanto na compressão como na tração. Em seguida, BALDOVINO et al. [17] analisaram os efeitos de adição de cal de outro solo siltoso da FG usando a energia Proctor normal aos 90 dias de cura. Os resultados demostraram um acréscimo na compressão simples e na tração indireta de até $75 \%$. Recentemente MOREIRA et al. [22] melhoraram um solo silto-arenoso da FG com cimento e resíduo de telha moída, obtendo aumento na compressão simples, influenciada diretamente pelos vazios e volume de cimento adicionado. BALDOVINO et al. [23] estabeleceram as equações de dosagem para um solo silto-arenoso da FG com adição de três tipos de cimento. MOREIRA et. al. [1] usaram resíduos da construção e demolição civil (RCD) para estabilizar granulometricamente um solo argiloso da FG. Os autores concluíram que a inclusão de RCD torna viável solos finos da FG para construção de camadas de pavimentos. BALDOVINO et al. [24] melhoram a resistência à compressão simples e durabilidade de um solo siltoso estabilizado com resíduo de vidro em pó e cimento. Por outro lado, BALDOVINO et. al. [23] e BALDOVINO e IZZO [25] melhoram um solo fino da FG usando cimento de alta resistência inicial para aplicação em pavimentação. Contudo, de acordo à literatura, não foram realizados estudos de estabilização dos solos da FG usando cinza de celulose e cal, assim como não se tem notícia de estudos desta natureza em outros solos. Por isso, este estudo propõe estudar as propriedades mecânicas de um solo característico da terceira camada da FG (camada amarela) usando cal hidratada e cinza de celulose, com isto se introduz um novo geo-material na literatura e se emprega um procedimento alternativo na estabilização dos solos usando um resíduo que pode ser aproveitável na construção civil. 


\section{PROGRAMA EXPERIMENTAL}

O programa experimental foi dividido em duas etapas. A primeira foi a realização dos ensaios de caracterização do solo, da cinza de celulose e da cal dolomítica hidratada, na qual se avaliou a granulometria do solo de acordo à norma ASTM D2487 [26]Compensation and Liability Act (CERCLA, os limites de Atterberg do solo de acordo às normas NBR 7180-84 [27] e NBR 6459-84 [28], a massa especifica real dos grãos do solo de acordo à norma ASTM D854 [29], a massa especifica real dos grãos da cinza de celulose e da cal hidratada em pó de acordo à norma NBR 16605-17 [30] e as propriedades de compactação do solo com os diferentes teores de cinza e cal por meio da avaliação da energia Proctor normal de acordo à norma NBR 7182 [31]. Na segunda etapa foram realizadas a moldagem, a cura e o rompimento dos corpos de prova solo-cinza-cal submetidos a ensaios de compressão simples e tração por compressão diametral em diferentes tempos de cura, assim como moldagem, imersão e ruptura dos corpos de prova submetidos a ensaios de CBR. No fim das duas etapas, uma amostra representativa de uma mistura solo-cinza-cal com 90 dias de cura foi submetida à Espectrometria por Energia Dispersiva (EDS) de Raios-X.

\subsection{Materiais}

Um solo siltoso de cor amarela da Formação Guabirotuba (FG), cinza de celulose da indústria da produção de papel, cal dolomítica hidratada e água destilada foram os materiais utilizados na pesquisa. A amostra de solo foi coletada num talude rodoviário a $3 \mathrm{~m}$ do nível do terreno (terceira camada da FG) natural no município de São José dos Pinhais, próximo da cidade de Curitiba (Brasil), de maneira manual em estado deformado, evitando uma possível contaminação e em quantidade suficiente para a realização de todos os ensaios. Um solo com características semelhantes da FG de cor vermelha já foi utilizado em estudos prévios por BALDOVINO et al. [5,17] para estabilização com cal hidratada. A cal hidratada foi fornecida por um produtor local e apresentou grãos com densidade $2,39 \mathrm{~g} / \mathrm{cm}^{3}$ e uma porcentagem passante pela peneira $\# 0,075 \mathrm{~mm}$ de $95 \%$.

A cinza de celulose foi coletada em uma empresa situada na cidade de Canoinhas - Santa Catarina, Brasil, que produz papel branco na produção de papel higiênico. Neste processo fabril é utilizado papel reciclado do qual são recuperadas as fibras de celulose das aparas para utilização na fabricação de outros produtos. Parte deste material é descartado como resíduo em forma líquida com alto teor de sólidos e assim faz-se necessária a retirada de grandes quantidades de líquidos do material formado, que é chamado de lodo primário. Este lodo é formado por caulim, celulose, traços não significativos de substâncias químicas e água. Desta forma, este material é classificado como resíduo da indústria de papel e celulose classe II A não inertes conforme norma técnica NBR 10.004 [32]. Após realizada a retirada da umidade do lodo, este é submetido a uma calcinação em temperatura em torno de $900^{\circ} \mathrm{C}$, resultando no produto final que é a cinza utilizada no presente artigo. Finalmente, para a realização de todos os ensaios de caracterização dos solos, das misturas solo-cinza-cal e para a moldagem de corpos de prova foi usada água destilada a temperatura ambiente $\left(24 \pm 3^{\circ} \mathrm{C}\right)$ para evitar reações não desejadas e limitar o número de variáveis no estudo.

A Tabela 1 apresenta as propriedades físicas do solo e da cinza de celulose. Segundo o Sistema Unificado de Classificação de Solos (SUCS), o solo é classificado como um silte elástico arenoso (MH). O solo, de cor amarela apresenta uma porcentagem de areia grossa de $5 \%$; areia média de $12 \%$; areia fina de $18 \%$; silte $60 \%$ e de argila de $5 \%$, sendo que a porcentagem de silte $(0,002 \mathrm{~mm}<\phi<0,075 \mathrm{~mm})$ compõe a maior parcela do solo. Durante os ensaios de limites de Atterberg, foi percebido que a cinza de celulose não apresenta plasticidade enquanto o solo possui uma plasticidade de $14,86 \%$ e uma massa específica real dos grãos de $2,62 \mathrm{~g} / \mathrm{cm}^{3}$.

A Tabela 2 exibe a composição química do solo e da cinza determinadas por fluorescência de raios-X. As propriedades químicas da cal, também mostradas na Tabela 2, foram fornecidas pelo produtor e as físicas foram calculadas no laboratório. Nota-se que o solo é composto principalmente por sílica e alumina com pequena quantidade de trióxido de enxofre. Adicionalmente, a Tabela 3 apresenta as propriedades de compactação do solo nas três energias de acordo com a norma NBR 7182 [31]. Como típico de solos finos, encontrou-se um aumento no peso específico seco máximo $\left(\gamma_{\mathrm{d}-\max }\right)$ e uma diminuição no teor de umidade ótimo $\left(\omega_{\mathrm{o}}\right)$ devido ao aumento de energia. O ponto máximo alcançado na energia modificada, segundo a Tabela 3, encontra-se em $\gamma_{\mathrm{d}-\max }=16,75 \mathrm{kN} / \mathrm{m}^{3}$ e $\omega_{\mathrm{o}}=14,5 \%$. 


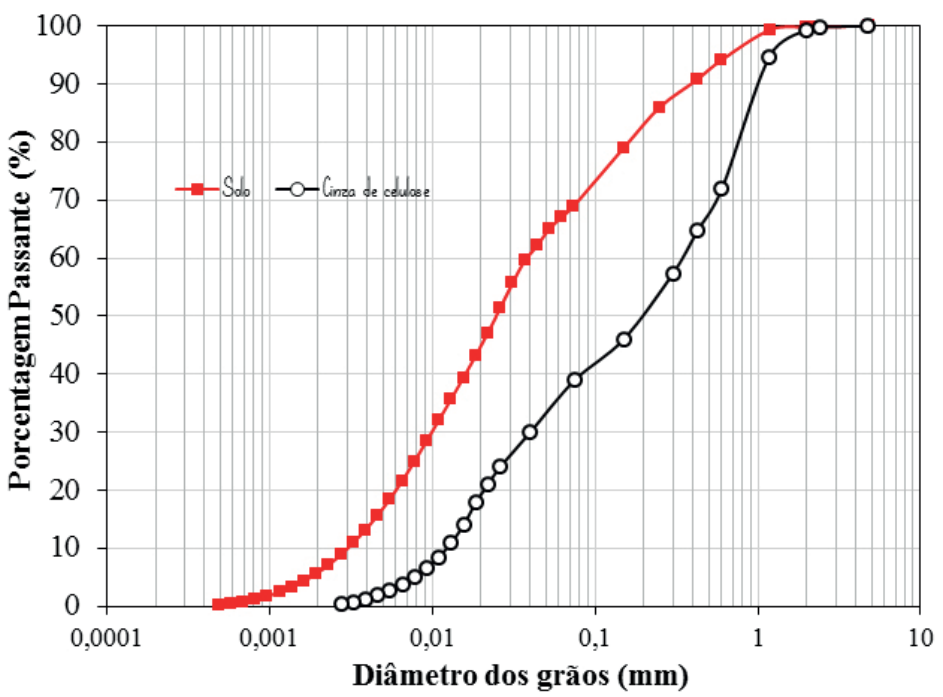

Figura 1: Curva de distribuição granulométrica do solo siltoso e da cinza de celulose

Tabela 1: Propriedades físicas do solo e da cinza de celulose

\begin{tabular}{|c|c|c|}
\hline \multirow{2}{*}{ PROPRIEDADE } & \multicolumn{2}{|c|}{ VALOR } \\
\hline & SOLO & CINZA DE CELULOSE \\
\hline Limite de liquidez, $\%$ & 50,82 & - \\
\hline Limite de plasticidade, $\%$ & 35,96 & - \\
\hline Índice de plasticidade, $\%$ & 14,86 & Não plástico \\
\hline Massa especifica real dos grãos & 2,62 & 2,31 \\
\hline Areia grossa $(0,6 \mathrm{~mm}<$ diâmetro $<2 \mathrm{~mm}), \%$ & 5 & 30 \\
\hline Areia média $(0,2 \mathrm{~mm}<$ diâmetro $<0,6 \mathrm{~mm}), \%$ & 12 & 20 \\
\hline Areia fina $(0,06 \mathrm{~mm}<$ diâmetro $<0,2 \mathrm{~mm}), \%$ & 18 & 15 \\
\hline Silte $(0,002 \mathrm{~mm}<$ diâmetro $<0,06 \mathrm{~mm}), \%$ & 60 & 35 \\
\hline Argila (diâmetro $<0,002 \mathrm{~mm}$ ), \% & 5 & - \\
\hline Diâmetro efetivo $\left(d_{10}\right), \mathrm{mm}$ & 0,003 & 0,013 \\
\hline Diâmetro passante $30 \%\left(d_{30}\right), \mathrm{mm}$ & 0,01 & 0,03 \\
\hline Diâmetro médio $\left(d_{50}\right), \mathrm{mm}$ & 0,025 & 0,2 \\
\hline Diâmetro passante $60 \%\left(d_{60}\right), \mathrm{mm}$ & 0,038 & 0,35 \\
\hline Diâmetro passante $90 \%\left(d_{90}\right), \mathrm{mm}$ & 0,3 & 1 \\
\hline Coeficiente de uniformidade (i.e., $C_{\mathrm{u}}=d_{60} / d_{10}$ ) & 8,33 & 26,92 \\
\hline Coeficiente de curvatura [i.e., $\left.C_{\mathrm{c}}=\left(d_{30}\right)^{2} /\left(d_{10} \times d_{60}\right)\right]$ & 1,33 & 0.35 \\
\hline Classificação segundo o SUCS & $\mathrm{MH}$ & - \\
\hline UCS- Solo virgem, $\mathrm{kPa}$ & 104,58 & $\mathrm{NC}$ \\
\hline STS-Solo virgem, $\mathrm{kPa}$ & 16,62 & $\mathrm{NC}$ \\
\hline Relação STS/UCS -Solo virgem & 0,16 & - \\
\hline$\phi$ - Solo virgem, $\left({ }^{\circ}\right)$ & 26 & $\mathrm{NC}$ \\
\hline Coesão- Solo virgem, $\mathrm{kPa}$ & 23 & $\mathrm{NC}$ \\
\hline Cor & Amarelo & Cinza marrom \\
\hline
\end{tabular}


Tabela 2: Propriedades químicas do solo e da cinza de celulose

\begin{tabular}{l|c|c|c}
\hline \multirow{2}{*}{ COMPOSTO } & \multicolumn{3}{|c}{ CONCENTRAÇÃO EM PESO (\%) } \\
\cline { 2 - 4 } & SOLO & CINZA DE CELULOSE & CAL DOLOMÍTICA HIDRATADA \\
\hline $\mathrm{SiO}_{2}$ & 48,78 & 8,8 & 0,70 \\
\hline $\mathrm{Al}_{3} \mathrm{O}_{3}$ & 44,51 & 8,3 & 0,40 \\
\hline $\mathrm{Fe}_{2} \mathrm{O}_{3}$ & 0,61 & 0,7 & 0,20 \\
\hline $\mathrm{CaO}$ & - & 55,6 & 63,2 \\
\hline $\mathrm{MgO}$ & - & 0,9 & 10,4 \\
\hline $\mathrm{K}_{2} \mathrm{O}$ & 0,84 & 0,2 & 0,30 \\
\hline $\mathrm{Na}_{2} \mathrm{O}$ & - & 0,1 & 0,1 \\
\hline $\mathrm{TiO}_{2}$ & 0,92 & 0,4 & 0,2 \\
\hline $\mathrm{MnO}$ & - & 0,1 & - \\
\hline $\mathrm{P}_{2} \mathrm{O}_{5}$ & - & 0,2 & - \\
\hline $\mathrm{SO} \mathrm{F}_{3}$ & 4,12 & 1 & - \\
\hline $\mathrm{SrO}$ & - & 0,2 & - \\
\hline $\mathrm{Cl}$ & - & 0,1 & - \\
\hline $\mathrm{ZnO}$ & - & 0,1 & - \\
\hline $\mathrm{CuO}$ & - & 0,1 & - \\
\hline $\mathrm{Perda}$ a fogo & & 23,9 & 24,5 \\
\hline
\end{tabular}

Tabela 3: Propriedades de compactação do solo

\begin{tabular}{|c|c|c|c|c|c|c|}
\hline \multirow[b]{2}{*}{ SOLO } & \multicolumn{3}{|c|}{ PESO ESPECÍFICO SECO MÁXIMO (kN/m³) } & \multicolumn{3}{|c|}{ TEOR DE UMIDADE ÓTIMO (\%) } \\
\hline & $\begin{array}{l}\text { ENERGIA } \\
\text { NORMAL }\end{array}$ & $\begin{array}{c}\text { ENERGIA } \\
\text { INTERMEDIÁRIA }\end{array}$ & $\begin{array}{c}\text { ENERGIA } \\
\text { MODIFICADA }\end{array}$ & $\begin{array}{l}\text { ENERGIA } \\
\text { NORMAL }\end{array}$ & $\begin{array}{c}\text { ENERGIA } \\
\text { INTERMEDIÁRIA }\end{array}$ & $\begin{array}{c}\text { ENERGIA } \\
\text { MODIFICADA }\end{array}$ \\
\hline $\begin{array}{c}\text { Silte } \\
\text { amarelo }\end{array}$ & 13,72 & 15,43 & 16,75 & 26,5 & 20,5 & 14,5 \\
\hline
\end{tabular}

\subsection{Fixação dos teores de cinza, teor de cal, tempo de cura e pontos de moldagem}

Para a determinação de um teor mínimo de cal (L) foi utilizado o método Eades e Grim [33] também chamado "Optimum Lime Content" ou OLC. Este método consiste em adicionar cal à mistura e realizar medidas do pH da mesma. Pelo método do OCL, o teor mínimo de cal é aquele que leva a um valor máximo e constante de $\mathrm{pH}$ aproximado de 12,4 que representa o teor de cal para satisfazer as reações iniciais e troca catiônica. O método consiste na mistura de $20 \mathrm{~g}$ de solo-cinza estabilizado peneirado passante pela peneira $425 \mu \mathrm{m}$ e $100 \mathrm{ml}$ de água destilada com posterior agitação por 30 segundos iniciais e depois por mais 30 segundos a cada 10 minutos durante uma hora. $\mathrm{O}$ pH da mistura resultante é então testado com um medidor de $\mathrm{pH}$ calibrado para uma solução padrão de $\mathrm{pH}=12$. O OLC corresponde ao teor mínimo de cal necessário para produzir um $\mathrm{pH}$ do solo de 12,4, nomeadamente uma solução saturada de cal. Embora os testes sejam conduzidos na fração fina do material estabilizado, ou seja, aquela fração mais reativa à estabilização de cal, presume-se que os resultados se apliquem a toda a classificação do material [34].

Foram adicionados teores de cal entre 3 e 7\% em relação a várias misturas de solo-cinza (usando teores de cinza entre 5 e $20 \%$ e solo passantes na peneira $425 \mu \mathrm{m}$ ). As misturas solo-cinza alcançaram um valor de pH próximo a 12,4 quando adicionado $5 \%$ de cal em pó até uma porcentagem de $20 \%$ de cinza. Assim, o teor de cal escolhido foi de $5 \%$ em referência à massa seca do solo e os teores de cinza escolhidos foram 5\%,10\%,15\% e 20\% também em referência à massa seca do solo. Desta forma, foram realizadas 4 misturas solo-cal-cinza: Solo $+5 \%$ cal $+5 \%$ cinza, Solo $+5 \%$ cal $+10 \%$ cinza, Solo $+5 \%$ cal $+15 \%$ cinza e Solo $+5 \%$ cal $+20 \%$ cinza; e uma mistura de controle do solo em estado virgem, sem adição de cal nem de cinza. Uma vez que as reações pozolânicas solo-cal-cinza se dão lentamente, foram escolhidos tempos de cura de até 90 -d (dias) sendo assim propostos 3 diferentes momentos para avaliar a resistência mecânica das misturas estudadas: 14-d, 28-d e 90-d.

Após a fixação dos teores de cinza e cal e os tempos de cura, procedeu-se com a realização dos ensaios de compac- 
tação na energia de Proctor normal segundo a norma NBR 7182 [31] para cada mistura a fim de se estabelecer os pontos de moldagem (i.e. peso especifico seco máximo e teor de umidade ótimo de cada mistura). A Figura 2 apresenta a curva de compactação do solo, a curva de cada mistura solo-cinza-cal e as linhas de saturação (i.e. 100\%) do solo e da mistura com maior adição de cinza e cal (5\%L+20\% cinza). Em referência a esses resultados, a Tabela 4 estabelece os critérios de moldagem para cada mistura tendo em consideração o ponto ótimo de cada curva $\left[\gamma_{\text {d-max }}, \omega_{0}\right.$ e grau de saturação/\%]. Estes pontos de moldagem são definidos estrategicamente considerando possíveis condições de campo, entre $13,80 \mathrm{kN} / \mathrm{m}^{3}$ e $11,80 \mathrm{kN} /$ $\mathrm{m}^{3}$, com uma variação do peso específico seco. Pontos de moldagem estratégicos para estudar solos melhorados já foram utilizados anteriormente por RIOS et al. [35], FESTUGATO et al. [36] e CONSOLI et al. [37].

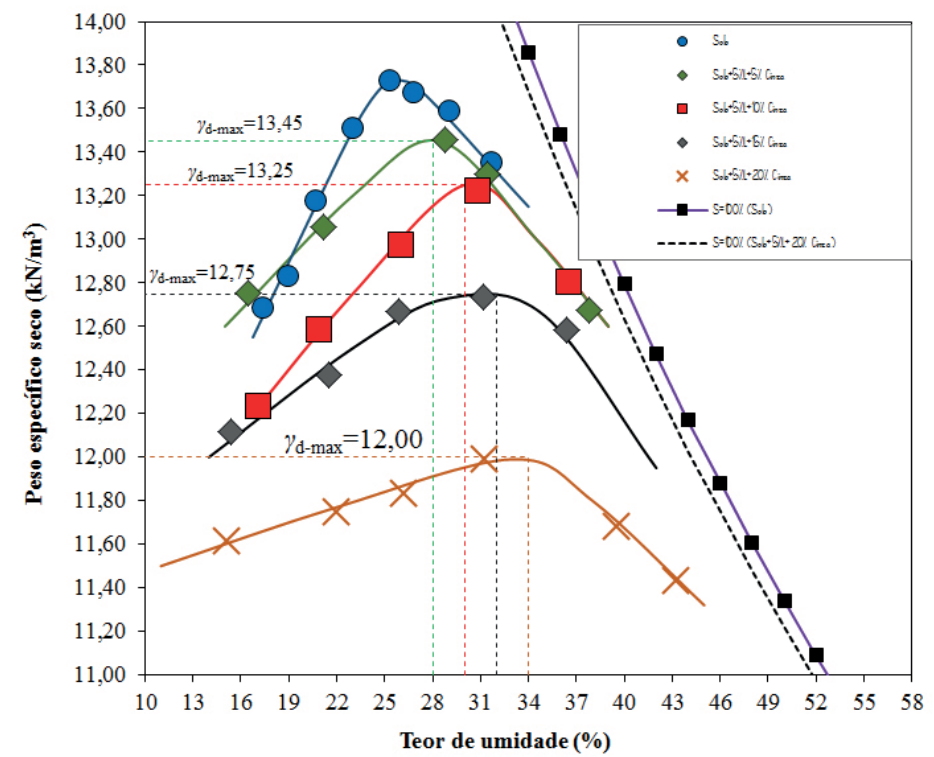

Figura 2: Curva de compactação do solo e das misturas solo-cinza de celulose-cal

Tabela 4: Definição dos pontos de moldagem

\begin{tabular}{l|c|c|c}
\hline MISTURA & $\gamma_{\mathbf{d}-\max }\left(\mathbf{k N} / \mathbf{m}^{\mathbf{3}}\right)$ & $\omega_{\mathbf{0}}(\mathbf{\%})$ & GRAU DE SATURAÇÃO/\% \\
\hline Solo (Controle) & 13,72 & 26,5 & 0,75 \\
\hline Solo+5\%L+5\% Cinza & 13,45 & 28 & 0,78 \\
\hline Solo+5\%L+15\% Cinza & 13,25 & 30 & 0,82 \\
\hline Solo+5\%L+20\% Cinza & 12,75 & 32 & 0,81 \\
\hline Solo+5\%L+25\% Cinza & 12,00 & 34 & 0,77 \\
\hline
\end{tabular}

\subsection{Moldagem dos corpos de prova e ensaios de resistência mecânica}

Para os ensaios de compressão simples e tração por compressão diametral foram moldados corpos de prova de $100 \mathrm{~mm}$ de altura e $50 \mathrm{~mm}$ de diâmetro. Depois da coleta em campo, o solo foi seco, totalmente, em estufa à temperatura de $100 \pm 5^{\circ} \mathrm{C}$, e colocado em porções uniformemente distribuídas para ser misturado com a cinza e posteriormente com a cal (em 5\%). Adicionou-se a quantidade de cinza seca em referência ao peso seco da amostra do solo em quatro teores diferentes de adição $(5 \%, 10 \%, 15 \%$ e $20 \%)$ de acordo aos ensaios de pH e OLC. Logo depois, adicionou-se a quantidade de cal em pó em referência à massa seca do solo com um teor fixo de $5 \%$.

Realizou-se a mistura do solo com a cinza e a cal de modo que as misturas ficassem as mais homogêneas possíveis. Em seguida, foi adicionada uma porcentagem de água em peso, sendo esta porcentagem referente ao teor de umidade ótimo dos pontos de moldagem estabelecidos na Tabela $4\left(\omega_{\mathrm{o}}\right)$. A mistura do solo-cinza-cal com a água destilada foi realizada em um período não superior a 5 minutos, com isto tentando minimizar as reações da cal com a água antes do processo de moldagem dos corpos de prova. As amostras para a moldagem dos corpos de prova foram compactadas estaticamente em três camadas com um molde de aço inox com diâmetro interno de $50 \mathrm{~mm}$, altura de $100 \mathrm{~mm}$ e espessura de $5 \mathrm{~mm}$, nas condições de compactação mostradas na Tabela 4. Para assegurar o peso específico seco aparente de moldagem $\left(\gamma_{\text {d-max }}\right)$ foi realizado o cálculo do volume do molde e do peso de mistura úmida necessários para cada corpo de prova. Após esses cálculos, foi pesada a quantidade necessária de material para cada corpo de prova. A moldagem foi feita com a ajuda de uma 
prensa hidráulica manual. Depois de cada processo de moldagem, três amostras da mistura eram tomadas para medir o teor de umidade em estufa durante 24 horas para assegurar o valor de $\omega_{0}$.

Os corpos de prova foram pesados em uma balança de precisão de $0,01 \mathrm{~g}$ e as dimensões do mesmo eram medidas com o uso de um paquímetro de $0,1 \mathrm{~mm}$ de erro. Os corpos de provas extraídos do molde foram envolvidos com plástico filme transparente para manter o teor de umidade. Por último, os corpos de prova foram armazenados em câmara úmida para processo de cura durante 14,28 e 90 dias (a temperatura média de $24^{\circ} \mathrm{C}$ ) para prevenir mudanças significativas de umidade até o dia do ensaio. As amostras tinham que respeitar os seguintes erros máximos para serem usadas nos ensaios de compressão simples e de tração por compressão diametral: dimensões das amostras com diâmetro de $\pm 0,5 \mathrm{~mm}$ e altura de $\pm 1 \mathrm{~mm}$, peso específico aparente seco $\left(\gamma_{\mathrm{d}}\right)$ de $\pm 1 \%$ e teor de umidade $(\omega) \mathbf{d e} \pm \mathbf{0 , 5 \%}$. Os valores de $\mathrm{q}_{\mathrm{u}}$ e $\mathrm{q}_{\mathrm{t}}$ são expressos em função da porosidade inicial de moldagem $(\eta)$ para qualquer teor de cal $(L)$, teor de cinza de celuse $\left(C_{i}\right)$ e peso especifico seco aparente de moldagem, e é calculada com a Equação ([5, 37]):

$$
\eta=100-100\left[\left(\frac{\gamma_{d}}{1+L+C i}\right)\left(\frac{1}{\gamma_{S S}}+\frac{L}{\gamma_{S L}}+\frac{C i}{\gamma_{S C i}}\right)\right]
$$

Onde $\gamma_{S S}, \gamma_{S L}$ e $\gamma_{S C i}$ são a massa específica real dos grãos do solo, da cal e da cinza, respectivamente. $\gamma_{d}$ é o peso específico seco de moldagem. Para cada ponto de moldagem ou mistura foram moldados 6 corpos de prova (3 para compressão e 3 para tração). No total, foram compactadas 72 amostras para estes dois ensaios.

Para os ensaios de CBR, foram compactadas amostras de diâmetro de $152 \mathrm{~mm}$ e 114,3 mm de altura usando um espaçador de 63,5 $\mathrm{mm}$ usando a energia Proctor normal (5 camadas usando 12 golpes em cada uma delas) como estabelecido na norma brasileira ABNT 9895 [38]. Após a compactação, sobre o corpo de prova dentro do molde cilíndrico, no espaço deixado pelo disco espaçador, foi colocado o prato com haste perfurado e sobre este o disco anelar com uma sobrecarga de 5 libras. Sobre a haste do prato perfurado, foi apoiado o relógio comparador fixado no porta-extensômetro, anotando-se a leitura inicial e a leitura depois de 96 horas. Assim, coloca-se o corpo de prova imerso por 4 dias. Após esse período, o corpo de prova foi retirado para a realização do ensaio de resistência à penetração usando um pistão padrão. Para cada mistura foram compactadas 3 amostras, anotando no final uma média aritmética dos resultados obtidos nas duas fases do ensaio: expansão e penetração.

\subsection{Ensaios de compressão simples, tração por compressão diametral e CBR}

Os procedimentos dos ensaios de compressão simples e tração por compressão diametral seguiram as normas brasileiras NBR 5739 [39] e NBR 7222 [40], respectivamente. Para a realização dos ensaios de compressão simples e tração por compressão diametral foi usada uma prensa automática com anéis calibrados para carga axial com capacidade de $10 \mathrm{kN}$. Os ensaios foram feitos com um sistema automatizado, medindo, principalmente, a força aplicada, com resolução de 2,5 N, a deformação, com sensibilidade de $0,001 \mathrm{~mm}$, sendo a velocidade do ensaio de $1,15 \mathrm{~mm} / \mathrm{min}$. A resistência a compressão simples é o valor da carga máxima de ruptura do material ou o valor da pressão correspondente à carga na qual ocorre deformação específica do corpo de prova de solo de $20 \%$, naqueles casos em que a curva tensão-deformação axial não apresenta um pico máximo. Adota-se a resistência à compressão não confinada ou simples $\left(\mathrm{q}_{\mathrm{u}}\right)$ de acordo com a seguinte expressão, quando, no ensaio a curva tensão-deformação axial, alcança um pico máximo:

$$
q_{\mathrm{u}}=\frac{\mathrm{P}_{\mathrm{R}}}{\mathrm{A}_{\mathrm{T}}}
$$

Onde $\mathrm{P}_{\mathrm{R}}$ é a carga de ruptura no pico da curva tensão-deformação axial e $\mathrm{P}_{\mathrm{T}}$ é a área transversal corrigida do corpo de prova. Adotou-se a resistência à tração por compressão diametral $\left(\boldsymbol{q}_{\mathrm{t}}\right)$ de acordo com a seguinte expressão:

$$
q_{\mathrm{t}}=\frac{2 \mathrm{P}_{\mathrm{Rd}}}{\pi \mathrm{DH}}
$$

Onde $\mathrm{P}_{\mathrm{Rd}}$ é a carga de ruptura no pico da curva tensão-deformação do corpo de prova. O ensaio de tração por compressão diametral, também chamado de ensaio de tração indireta ou ensaio brasileiro, foi desenvolvido de maneira independente no Brasil e no Japão em 1943. O ensaio é realizado por meio da aplicação de uma carga de compressão em um corpo de prova cilíndrico que se encontra entre duas peças retangulares, com dimensões em função do diâmetro do corpo de prova, localizadas de maneira diametralmente opostas, conforme a Figura 1. 


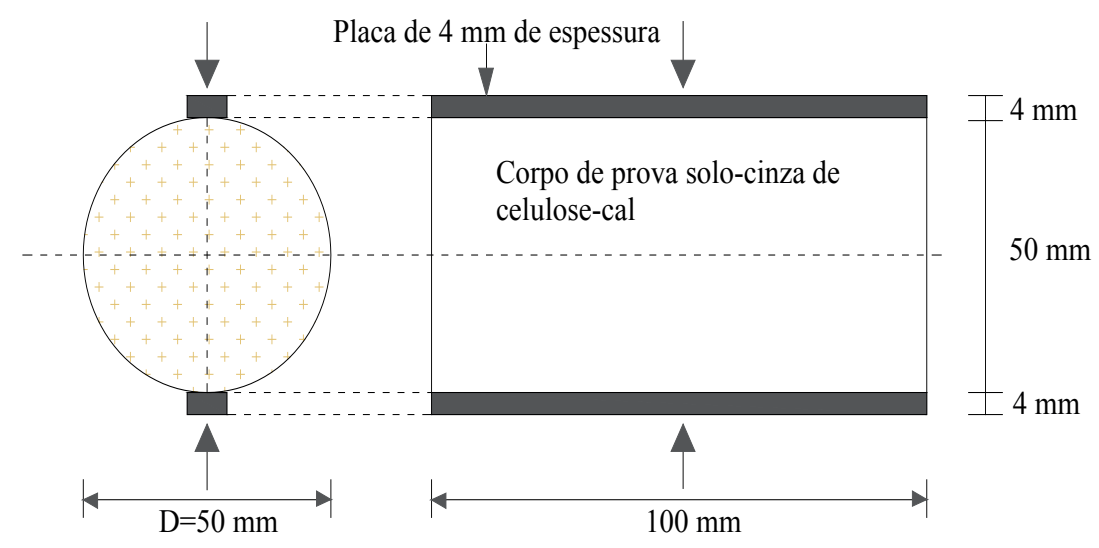

Figura 3: Corpo de prova solo-cinza de celulose-cal submetido ao ensaio de tração por compressão diametral

O ensaio de CBR seguiu o procedimento da norma brasileira ABNT 9895 [38], sendo composto por três etapas: compactação do corpo de prova segundo o método Proctor, obtenção da expansão e medida da resistência à penetração. Para os cálculos dos valores do CBR é adotado o maior dos valores obtidos para as tensões lidas ou corrigidas nas penetrações de 2,54 mm e de 5,08 mm. Consequentemente, o CBR é calculado como a tensão lida dividida por uma tensão padrão dada nas normas internacionais originarias do método.

\subsection{Microanálise química}

Microanálises químicas de uma amostra de solo-cinza-cal (S+5\%L+15\%Cinza) após 90 dias de cura foram determinadas usando Espectroscopia Dispersiva de Energia (EDS) com um X-ACT Oxford (Penta FET125 Precision) e micro-análise de massa usando um analisador de micro-massa a laser (LAMMA-1000, modelo X-ACT).

\section{APRESENTAÇÃO E DISCUSSÃO DOS RESULTADOS}

\subsection{Características da compactação das misturas solo-cinza-cal}

A Figura 4 apresenta os resultados da influência dos teores de cinza de celulose no peso específico seco máximo (PESM ou $\gamma_{\mathrm{d}-\max }$ ) e no teor de umidade ótimo (TUO ou $\omega_{\mathrm{o}}$ ) das curvas de compactação das misturas mostradas na Figura 2 e detalhado na Tabela 4 (obtidas da compactação na energia Proctor normal). Nota-se uma diminuição no peso específico seco máximo conforme é adicionado a quantidade seca de cinza de celulose. Em adição, um aumento no teor de umidade ótimo também é encontrado. Uma representativa mudança no peso máximo seco e umidade ótima foi observada para as amostras de solo estabilizadas com material de celulose e cal até $20 \%$ e $5 \%$, respectivamente. O aumento da cinza de celulose desde $5 \%$ para $20 \%$ causou grandes variações nas características de compactação das amostras de solo- $5 \%$ cal, diminuindo o peso específico seco máximo em $14 \%$ e aumentando a TOU em $30 \%$ em referência à curva de compactação do solo em estado virgem. Este comportamento deve-se à adição de materiais finos (cinza e cal) e com densidade menor $\left(2,39 \mathrm{~g} / \mathrm{cm}^{3} \mathrm{para}\right.$ a cal e $2,31 \mathrm{~g} / \mathrm{cm}^{3}$ para a cinza) em referência ao do solo $\left(2,62 \mathrm{~g} / \mathrm{cm}^{3}\right)$ que preencheram os vazios entre as maiores partículas do solo silto-arenoso e levaram a diminuir o peso dos sólidos na unidade de volume. BALDOVINO et al. também obteve uma diminuição do peso PESM e um aumento no TUO depois de adicionar cal hidratada a um solo siltoso da FG, devido a que a cal absorve grande quantidade de água [6]. ARULRAJAH et al. [3] ao adicionar subprodutos como cinza volante, escoria de alto forno e resíduo de cal para estabilizar RCD, obteve também uma diminuição no PESM nas misturas estudadas. Resultados de compactação semelhantes aos obtidos no presente estudo foram analisados por PHUMMIPHAN et al. [7] para misturas de cinza volante e escoria de alto forno na estabilização de um solo laterítico. Assim, os resultados mostrados na Figura 2 e Figura 4 são de acordo ao reportado na literatura. 




Figura 4: Influência do teor de cinza nas propriedades de compactação (Peso específico seco máximo-PESM e Teor de umidade ótimo-TUO) das misturas solo-cinza-cal

\subsection{Influência do teor de cinza na resistência à compressão simples, tração por compressão diametral e CBR}

A Figura 5 mostra os resultados da influência da adição de cinza de celulose na resistência à compressão simples $\left(\mathrm{q}_{u}\right)$ para 14-d, 28-d e 90-d de cura. Para 14-d, 28-d e 90-d de cura, a resistência à compressão simples aumentou de maneira proporcional desde 5 até $15 \%$ de adição de cinza. Depois de $15 \%$ cinza (até $20 \%$ de cinza), os valores de $\mathrm{q}_{u}$ diminuíram em média em $35 \%$. Em 14-d cura, $\mathrm{q}_{\mathrm{u}}$ aumentou em $25 \%$, desde $5 \%$ até $20 \%$ de cinza, para 28 -d e 90 -d cura o acréscimo de $\mathrm{q}_{\mathrm{u}}$ foi de $30 \%$ e $33 \%$, respectivamente. De forma geral, se obtiveram as máximas resistências $\mathrm{q}_{\mathrm{u}}$ quando adicionado $15 \%$ cinza na mistura solo $+5 \% \mathrm{~L}$ para todos os tempos de cura.



Figura 5: Influência do teor de cinza de celulose na resistência à compressão simples na mistura solo-5\% cal após 14, 28 e 90 dias de cura. 


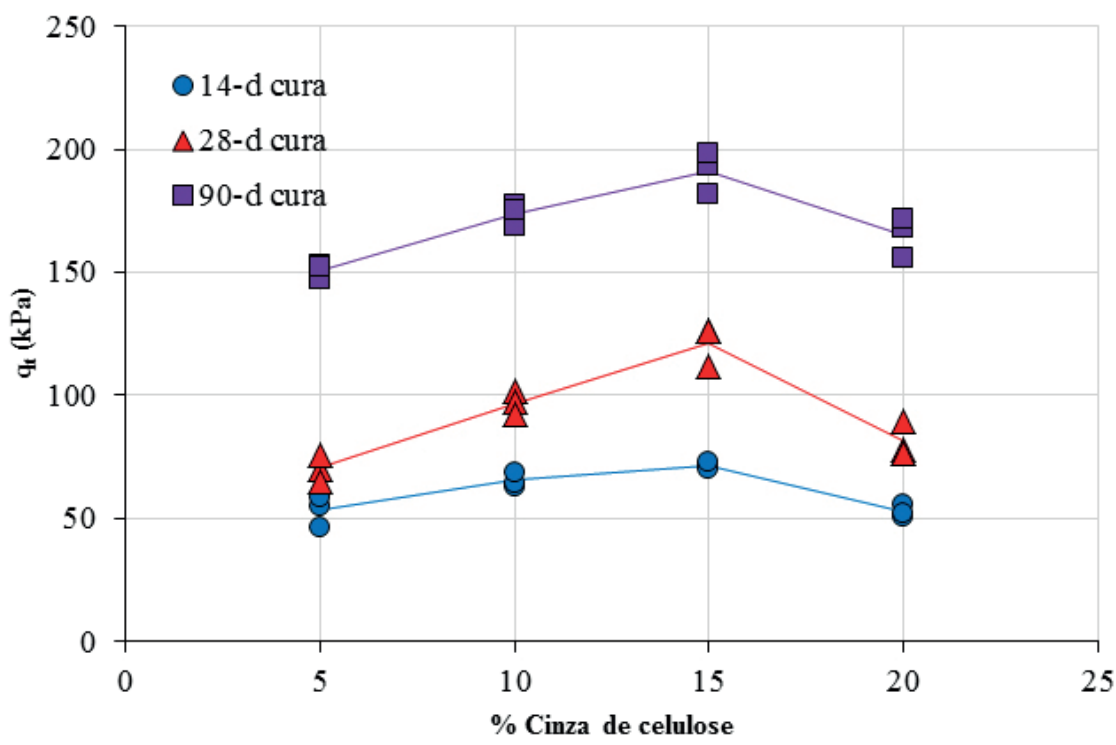

Figura 6: Influência do teor de cinza de celulose na resistência à tração por compressão diametral na mistura solo-5\% cal após 14, 28 e 90 dias de cura.

A Figura 6 apresenta a influência dos teores $5 \%, 10 \%, 15 \%$ e $20 \%$ de cinza de celulose na resistência à tração por compressão diametral ( $q_{t}$ ) para os tempos de cura de 14-d, 28-d e 90-d. De igual forma que para a compressão simples, a tração indireta aumentou proporcionalmente até $15 \%$ de cinza e caiu desde este teor até $20 \%$ de cinza. Descrevendo a diminuição de $\mathrm{q}_{\mathrm{t}}$ desde 15\%-20\% de cinza para cada tempo de cura, se tem que para 14-d os valores de $\mathrm{q}_{\mathrm{t}}$ diminuíram em $30 \%$, para $28-\mathrm{d} \mathrm{q}_{\mathrm{t}}$ diminui em $40 \%$ e finalmente para 90 -d a resistência à tração caiu $35 \%$. A diminuição da resistência mecânica (tanto compressão como tração) depois de $15 \%$ de adição de cinza de celulose deve-se principalmente a dois fatores: primeiro, a influência da porosidade [Equação (1)] e dos vazios da mistura solo-cinza-cal não exerceu maior atuação na resistência $q_{u}$ e à tração indireta $q_{t}$ do que o teor volumétrico de cal usado (i.e. quantidade de cal inserida no volume de solo para cada corpo de prova), de tal forma que um aumento na porosidade necessita de um incremento proporcionalmente maior no teor de cal, a fim de compensar o aumento dos vazios devido à falta de compactação e manter a resistência constante, e segundo, de acordo com a composição química da cinza de celulose mostrada na Tabela 2, uma parcela do material é inerte e inviabiliza reações pozolânicas na matriz das misturas além de ser um material ligeiramente menos pesado que o solo e que a cal, com uma densidade calculada de $2,31 \mathrm{~g} / \mathrm{cm}^{3}$. O anterior, somado ao fato de estar compactando em um peso específico seco menor em referência às outras misturas (i.e. solo-5\%L-5\%Cinza, solo-5\%L-10\%Cinza e solo-5\%L-15\%Cinza) compreende que o teor de $20 \%$ de cinza seja inviável já que diminui a resistência da mistura. Assim, uma análise da possível aplicação das misturas solo-cinza-cal em obras de engenharia geotécnica deve formular-se com a utilização de até $15 \%$ de cinza, sendo esta porcentagem a qual potencializa as maiores resistências.

Devido à dissolução da silica e alumina presente no solo e o óxido de cálcio presente na cal e na cinza de celulose, foi produzida uma reação pozolanica que aumentou a resistência das misturas. Este proceso é chamado de geopolimerização como reportado por ARULRAJAH et al. [3], em misturas de RCD e subprodutos como cinza volante. BALDOVINO et al. [17] obteve $1200 \mathrm{kPa}$ de resistência à compressão simples em 90 -d cura para misturas solo siltoso da FG-9\% de cal. Este valor é igual ao obtido com 15\%cinza de celulose e 5\% cal (ver Figura 5). Consequentemente, a adição de cinza de celulose diminui o consumo de cal. Em misturas solo da FG-7\% de cimento de alta resistência inicial curadas em 28-d, BALDOVINO et al. [2] obteve também $1200 \mathrm{kPa}$ de resistência à compressão simples. , BALDOVINO et al. [23] estabilizaram o solo usado no presente estudo com cimento. Após 28-d de cura, os autores encontraram que a resistência à compressão adicionando $9 \%$ de cimento foi de $1200 \mathrm{kPa}$ aproximadamente. Assim, comparando a estabilização do solo com cimento e com cinza de celulose-cal se pode concluir que o consumo de cimento também pode ser reduzido.

A Figura 7 apresenta em detalhe os materiais em estado puro usados na pesquisa: solo siltoso da FG, cinza de celulose e cal hidratada (Ver Figura 7c). Por outro lado, também é apresentado dois corpos de prova com adição e sem adição de cinza (Ver detalhe da Figura 7a) mostrando a mudança no aspecto sofrido pelo solo com a adição da cinza e da cal, tornando-se um pouco mais obscuro. A Figura $7 \mathrm{~b}$ mostra, os tipos de falhas comumente achadas durante os ensaios de tração e compressão: falha por compressão diametral e falha cisalhante (para compressão simples). A falha cisalhante é o tipo de falha mais encontrado durante ensaios de compressão axial para solos estabilizados, já que o aumento na resistência devido à estabilização química aumenta a rigidez. Outros tipos de falhas foram encontrados nos corpos de prova ensaiados como 
falha colunar com e sem formação de cone, mas a mais representava foi a cisalhante.

O ensaio CBR, desenvolvido antes da Segunda Guerra Mundial, ainda é o procedimento experimental mais usado para o projeto de pavimentos. Atualmente, o ensaio de CBR é particularmente usado para medir a qualidade das camadas granulares. Este ensaio mede a resistência do solo (ou solo estabilizado) à penetração por um pistão padrão em uma deformação específica. O índice CBR resulta de razões entre tensões medidas em certos níveis de penetração no material testado dividido pelo estresse medido em um solo padrão na mesma penetração. A execução do teste e os cálculos necessários são simples, o que torna o teste CBR particularmente popular em todos os lugares [41]. A Figura 8 mostra os resultados dos ensaios de expansão e CBR das misturas solo-cinza-cal. Os dados de expansão foram tomados após 96 horas de imersão dos corpos de prova em água destilada. Mostra-se a redução da expansão em 26 vezes com a adição de 5\% de cal e $15 \%$ de cinza de celulose. Com adição de 5\% de cinza obteve-se uma redução da expansão de $2,6 \%$ para $0,8 \%$ e para $10 \%$ de cinza a redução foi de $2,6 \%$ para $0,55 \%$ e finalmente para $20 \%$ de cinza, a diminuição foi de $2,6 \%$ para $0,33 \%$. Assim, a redução mais representativa da expansão das misturas quando adicionado $15 \%$ de cinza na presença de $5 \%$ de cal. Para os resultados de CBR, deu-se o mesmo efeito que para a expansão. O maior aumento se obteve quando adicionado $15 \%$ de cinza. Este aumento comparado com o CBR do solo virgem (3,53\%) foi de 140\%. Já para os outros teores o aumento do CBR em relação ao CBR do solo foi de 70\%, 105\% e 85\% para adições de cinza de 5\%, 10\% e 20\%, respectivamente.

De acordo à norma Brasileira do DNIT/2006 [42], valores de CBR maiores ao do subleito e menores a 20\% podem ser usados como reforço de subleito. Assim, todas as misturas propostas podem ser usadas para esta finalidade. No entanto, é recomendável usar $15 \%$ de cinza de celulose onde se obtém o maior valor de CBR e menor valor de expansão. Por outra parte, valores de compressão simples com $15 \%$ de cinza resultaram perto de $1200 \mathrm{kPa}$. Normas internacionais como a Americana TxDOT/2013 [43] sugerem que esse valor permitiria usar a mistura de 15\% como material de sub-base. No Brasil, também um geo-material como o solo-cimento com valor de resistência à compressão simples de $1200 \mathrm{kPa}$ pode ser usado como reforço de sub-base. Consequentemente, a cinza de celulose é um material potencialmente aplicável na construção civil.
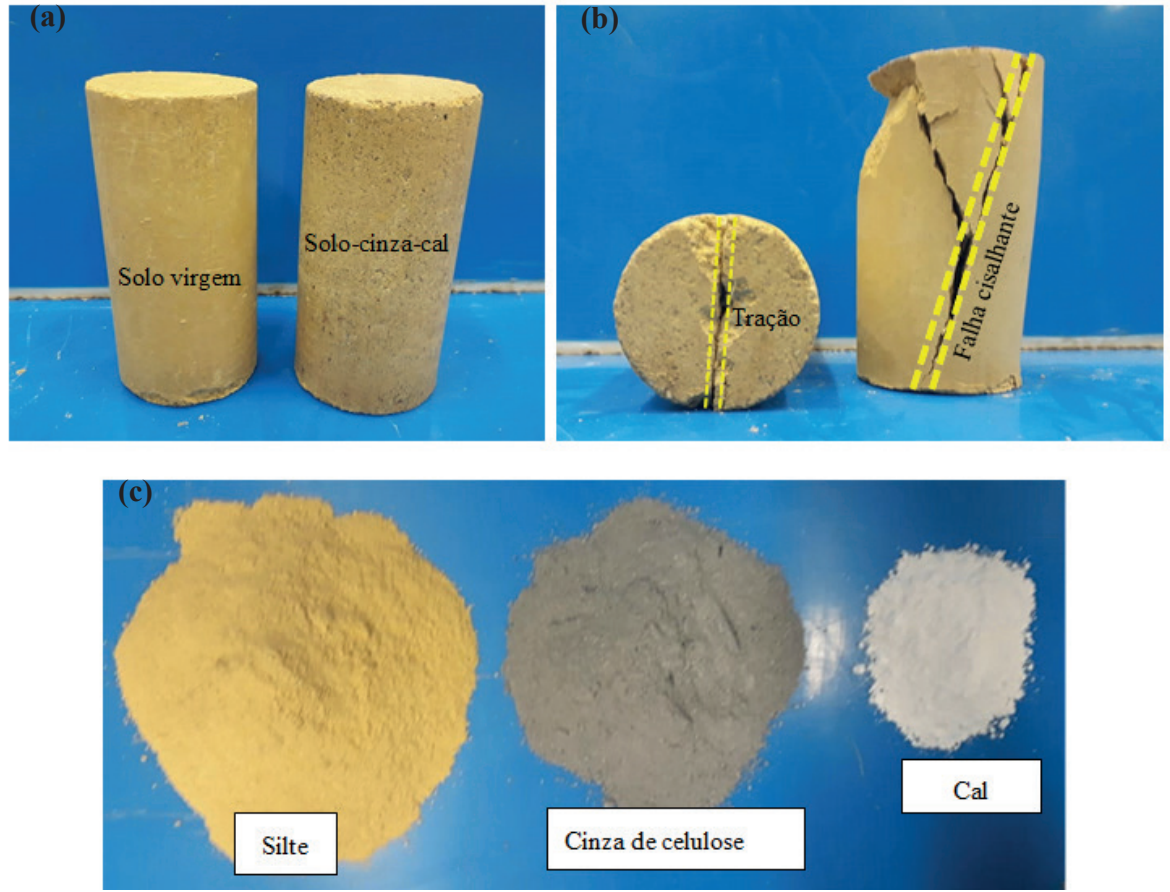

Figura 7: Materiais e exemplos de corpos de prova usados nesta pesquisa. a) Corpos de prova solo-cinza-cal. b) Corpos de prova após ensaios de compressão e tração. c) Materais em estado puro. 


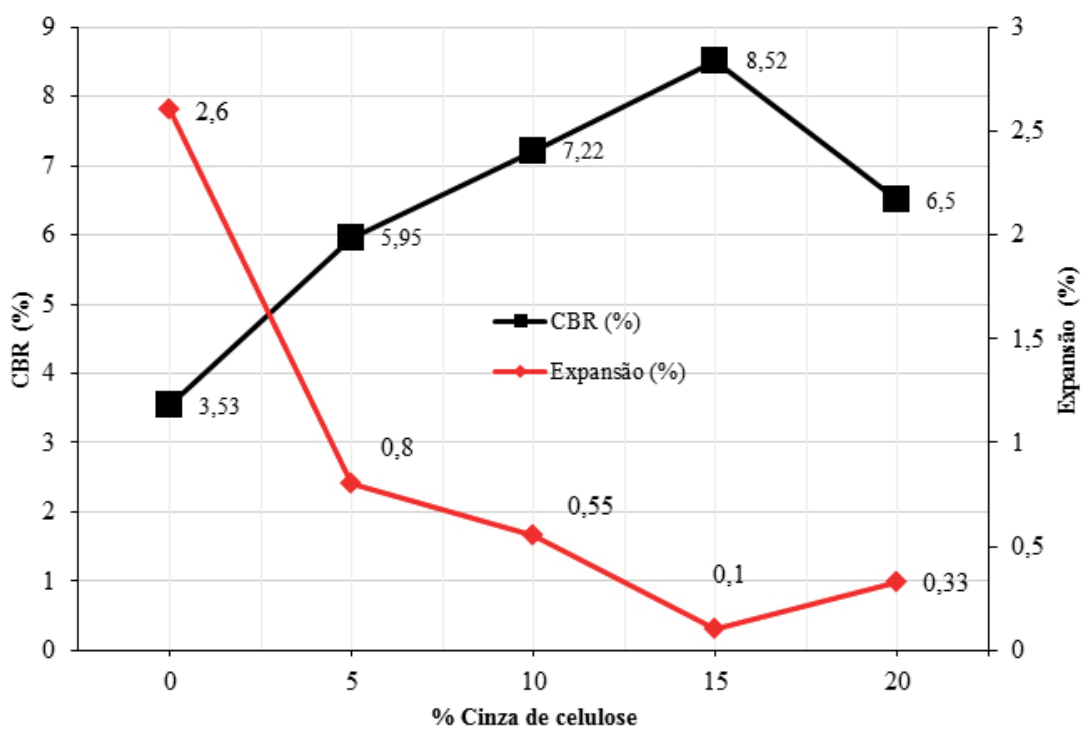

Figura 8: Influência do teor de cinza de celulose no CBR e expansão das misturas solo-cal-cinza

\subsection{Influência das relações de fase peso-volume na resistência mecânica das misturas}

A relação de aumento de resistência à compressão simples e à tração por compressão diametral é uma variável muito importante na mecânica de solos cimentados artificialmente, já que com a obtenção de uma fórmula geral de dosagem em função do tempo de cura e do teor de cinza/cal para o solo estudado, pode-se calcular a quantidade de cinza, cal, grau de compactação e o tempo de cura que se precisa empregar sobre o solo para obter uma resistência à compressão e tração desejada experimentalmente. Neste caso, aplica-se um modelo semiempírico baseado nas relações de fase peso-volume das misturas até uma porcentagem de 15\% de cinza, onde se obtém as maiores resistências mecânicas. O modelo está baseado no índice porosidade/teor volumétrico de cal. A porosidade das misturas pode ser calculada usando a Equação (1) e o teor volumétrico de cal é definido como a ração entre volume cal pelo volume de um corpo de prova [Equação (5)]. O teor volumétrico aumenta com o aumento do teor de cal enquanto a relação porosidade/teor volumétrico diminui.

$$
\mathrm{L}_{i v}=\frac{100\left(\left(\frac{\gamma_{d} \mathrm{~V}_{\mathrm{s}}}{1+L+C i}(\mathrm{~L})\right) / \gamma_{S L}\right)}{\mathrm{V}_{\mathrm{s}}}
$$

Onde Vs é o volume do corpo de prova solo-cinza-cal (aproximadamente $196 \mathrm{~cm}^{3}$ ). Nas Figuras 9a-9b apresenta-se a influência da relação porosidade/teor volumétrico de cal na resistência à compressão simples e à tração por compressão diametral para as amostras com 14-d, 28-d e 90-d de cura. Segundo CONSOLI et. al. [37] é possível encontrar uma tendência única dos pontos das Figuras 9a-9b elevando o teor volumétrico de cal $\left(\mathrm{L}_{\mathrm{iv}}\right)$ a um exponente. No caso da presente pesquisa o exponente com o qual os pontos se organizam (e se obtém o melhor coeficiente de determinação) é de 1,00.

Se as equações (das Figuras 9a-9b) que controlam $\mathrm{q}_{\mathrm{u}}$ e $\mathrm{q}_{\mathrm{t}}$ são dividas pela expressão $10^{2}\left(\eta / L_{\mathrm{iv}}\right)^{-0,50}$ se obtém uma constante que aumenta com o tempo de cura. A Figura 10 apresenta a evolução da resistência à tração e à compressão simples desde 14 até 90 dias de cura. $\mathrm{O}$ aumento do tempo de cura produz um aumento nos valores de $q_{\mathrm{t}}$ e $q_{\mathrm{u}}$ mostrando um aumento potencial com valores de coeficientes de determinação de $\mathrm{R}^{2}=0,99$ tanto para $q_{\mathrm{t}}$ como para $q_{\mathrm{u}}$. Assim, uma equação de dosagem para $q_{\mathrm{t}}$ e $q_{\mathrm{u}}$ pode ser proposta com a relação $\eta / L_{\mathrm{iv}}$ e com o tempo de cura (t). As expressões de dosagem para $q_{\mathrm{t}}$ e $q_{\mathrm{u}}$ são mostradas nas Eq. (5) e Eq. (6), respectivamente. Estas equações de dosagem podem ser empregadas dentre os limites de cinza de celulose, cal e grau de compactação usados nesta pesquisa. Autores como BALDOVINO et al. [17] e MOREIRA et al. [22] usaram também a relação porosidade/cal e porosidade/cimento para estabelecer equações que permitissem estimar a resistência dos solos estabilizados da FG.

$$
\begin{gathered}
\mathrm{q}_{\mathrm{t}}=41,88 \times \mathrm{t}^{0,36}\left[\frac{\eta}{L_{i v}}\right]^{-0,50}\left(\mathrm{R}^{2}=0,99\right) \\
\mathrm{q}_{\mathrm{u}}=531,21 \times \mathrm{t}^{0,53}\left[\frac{\eta}{L_{i v}}\right]^{-0,50}\left(\mathrm{R}^{2}=0,99\right)
\end{gathered}
$$



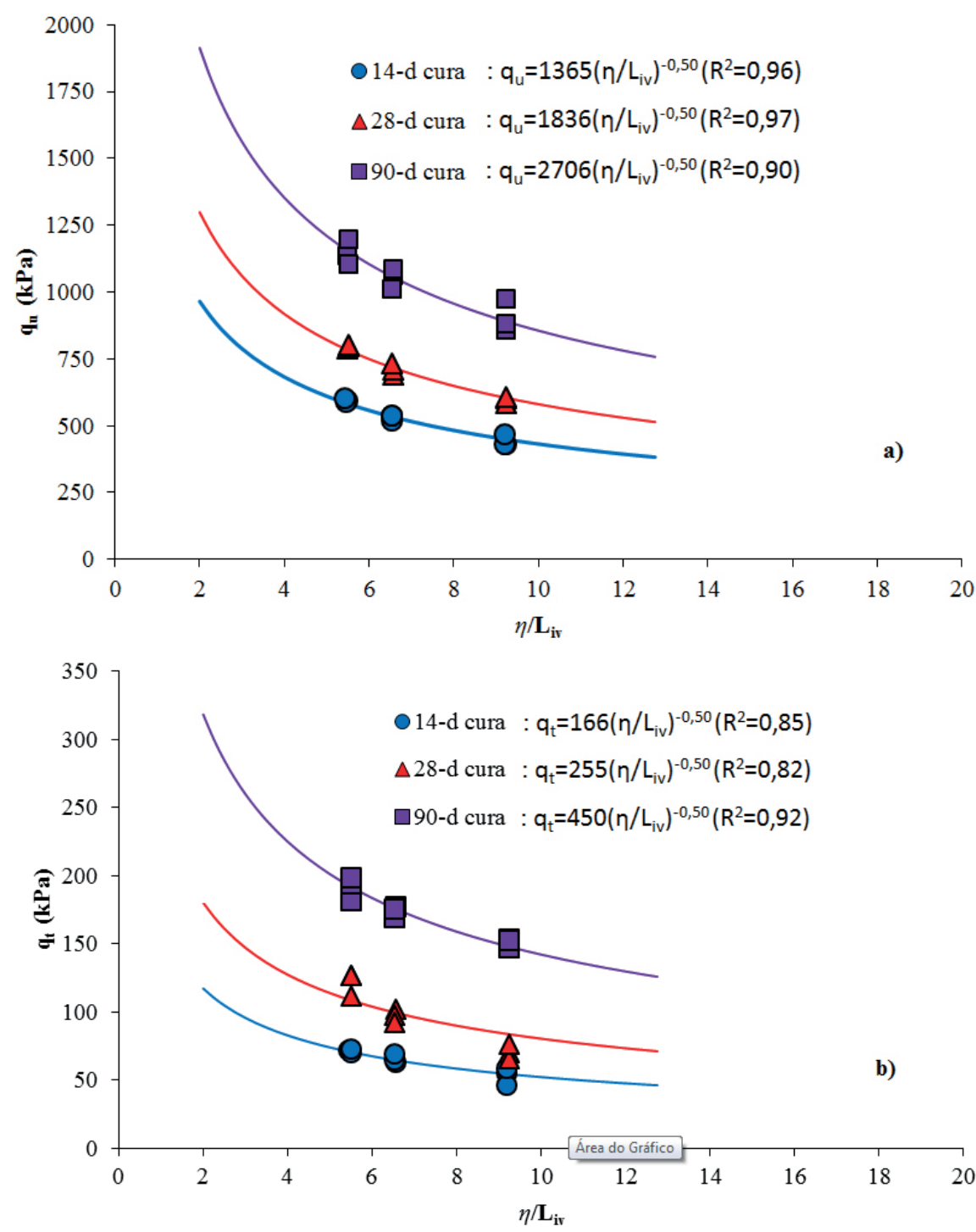

Figura 9: Influência da relação porosidade/teor volumétrico de cal $\left(\eta / \mathrm{L}_{\mathrm{iv}}\right)$ na resistência mecânica das misturas até $15 \%$ de cinza de celulose para os tempos de cura de 14-d, 28-d e 90-d. (a) $\eta / L_{\text {iv }} v s . q_{u^{*}}$ (b) $\eta / L_{i v} v s . q_{t^{*}}$

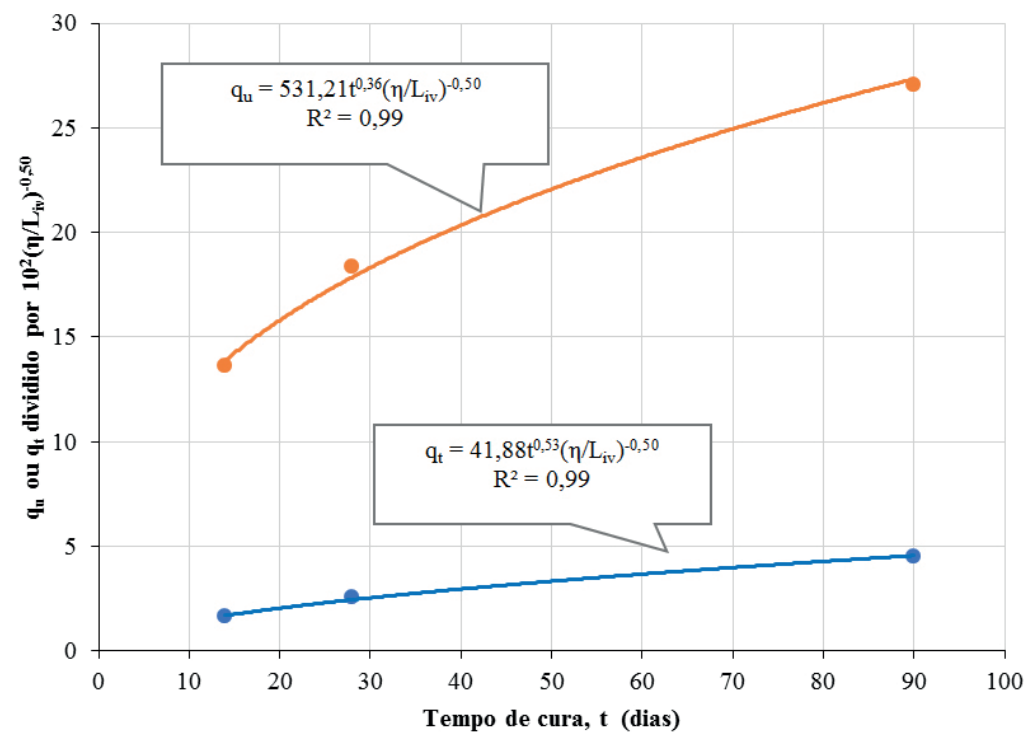

Figura 10: Equações de dosagem para a resistência à compressão simples e tração por compressão diametral usando os tempos de cura 14-d, 28-d e 90-d e a relação $10^{2}\left(\eta / \mathrm{L}_{\mathrm{iv}}\right)^{-0,50}$ dividido pelos valores das constantes $\mathrm{A}_{\mathrm{i}}$ correspondentes a cada tempo de cura. 


\subsection{Microanálise química}

A composição química da nova formação do geo-material foi testada pelo EDS. A microanálise é apresentada na Figura 11. O conteúdo de cada elemento químico na área (Figura 11) localizado na morfologia vítrea corresponde em grande parte aos resultados das análises de FRX (Tabela 2) das matérias-primas (solo, cinza e cal). Os resultados da microanálise demonstram um grande nível de heterogeneidade típica das matérias-primas e a não formação de novos minerais devido à ausência de elementos amorfos e à moderada temperatura de cura das misturas (aproximadamente $24^{\circ} \mathrm{C}$ ). A Figura 11 apresenta uma estrutura dispersa com porosidade da mistura ensaiada, mostrando também partículas de cinza que não reagiram completamente com a cal. Estudos prévios mencionam que algumas partículas não se dissolvem completamente dentro da matrix cimentada [7], mas ajudam a diminuir a porosidade.

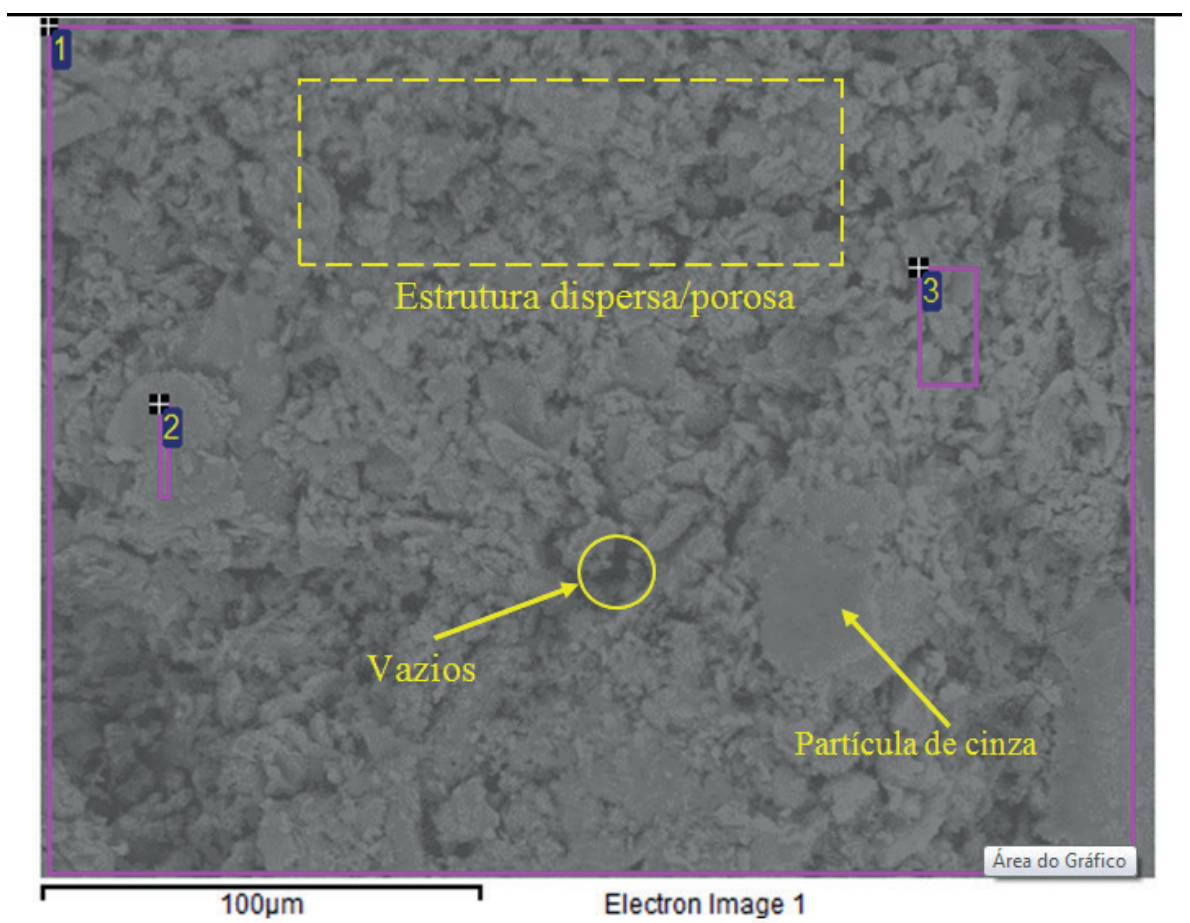

\begin{tabular}{l|lllllllll}
\hline Área & $\mathbf{C}$ & $\mathbf{O}$ & $\mathbf{M g}$ & $\mathbf{A l}$ & $\mathbf{S i}$ & $\mathbf{K}$ & $\mathbf{C a}$ & $\mathbf{T i}$ & $\mathbf{F e}$ \\
1 & 9.38 & 61.02 & & 9.96 & 10.55 & 0.34 & 3.22 & 0.89 & 4.65 \\
2 & & 63.12 & & 14.29 & 16.32 & & 3.29 & 0.65 & 2.32 \\
3 & 8.57 & 53.50 & 0.43 & 9.46 & 13.03 & 1.12 & 6.45 & 0.46 & 6.98 \\
Max. & 9.38 & 63.12 & 0.43 & 14.29 & 16.32 & 1.12 & 6.45 & 0.89 & 6.98 \\
Min. & 8.57 & 53.50 & 0.43 & 9.46 & 10.55 & 0.34 & 3.22 & 0.46 & 2.32 \\
\hline
\end{tabular}

Figura 11: Resultados da microanálise química em uma mistura solo-cinza-cal protótipo depois de 90-d cura usando a Microscopia Eletronica de Varredura (MEV) e a Espectroscopia por Dispersão de Energia (EDS). MEV da mistura Solo $+5 \% \mathrm{~L}+15 \%$ Cinza em escala de $100 \mu \mathrm{m}$ e as areas 1, 2 e 3 estudadas para a análise química usando o EDS [Acima]. Tabela dos detalhes da composição química nas áreas 1, 2 e 3 [Embaixo].

\subsection{Relações empíricas entre compressão simples e tração por compressão diametral}

Uma relação entre tração e compressão simples $\left(q_{t} / q_{u}\right)$ pode ser proposta usando a relação $\eta / L_{i v}$ e calculando-a de maneira direita. Se as equações que controlam a tração e a compressão das Figuras 9a-9b são divididas, uma constante é obtida para cada tempo de cura. Assim para 14-d, a constante $\mathrm{q}_{\mathrm{t}} / \mathrm{q}_{\mathrm{u}}=166 / 1365=0,12 ;$ para $28-\mathrm{d} \rightarrow \mathrm{q}_{\mathrm{t}} / \mathrm{q}_{\mathrm{u}}=255 / 1836=0,14$ e para $90-\mathrm{d} \rightarrow$ $\mathrm{q}_{\mathrm{t}} / \mathrm{q}_{\mathrm{u}}=450 / 2706=0,16$. A relação $\mathrm{q}_{\mathrm{t}} / \mathrm{q}_{\mathrm{u}}$ varia desde 0,12 até 0,16 dependendo do tempo de cura e de $\eta / \mathrm{L}_{\mathrm{iv}}$. Assim, usando a relação semiempirica $\eta / L_{\text {iv }}$ se obtém a relação $q_{t} / q_{u}$ de maneira linear. Por outro lado, se os dados de compressão e tração são organizados em um mesmo plano cartesiano, uma relação direta pode ser calculada. A Figura 12 apresenta a relação direta de $\mathrm{q}_{\mathrm{t}} / \mathrm{q}_{\mathrm{u}}$, deste modo a constante-relação se obtém uma forma potencial: $\mathrm{q}_{\mathrm{t}}=0,0115 \mathrm{q}_{\mathrm{u}}{ }^{1,38}\left(\mathrm{R}^{2}=0,97\right)$ com excelente coeficiente de determinação. No entanto, todos os dados experimentais de maneira direta apresentam uma relação linear entre $\mathrm{q}_{\mathrm{t}} / \mathrm{q}_{\mathrm{u}}=0,10$ e $\mathrm{q}_{\mathrm{t}} / \mathrm{q}_{\mathrm{u}}=0,18$ como é mostrado na Figura 12 .

Segundo DIAMBRA et al. [44], para solos arenosos cimentados artificialmente, a existência de uma relação entre as 
resistências à tração/compressão $\left(=\mathrm{q}_{\mathrm{t}} / \mathrm{q}_{\mathrm{u}}\right)$ é independente do tempo de cura e está governada, principalmente, pela relação à tração (ou propriedades de fricção) do cimento. Autores como CONSOLI et al. [45] calcularam uma relação $\mathrm{q}_{\mathrm{t}} / \mathrm{q}_{\mathrm{u}}$ de 0,13 para misturas de solos finos compactos com cimento Portland usando teores de umidade de moldagem de 17,20 e $23 \%$ e pesos específicos secos de moldagem entre 14 e $16 \mathrm{kN} / \mathrm{m}^{3}$. Logo, FESTUGATO et al. [36] fizeram misturas de um solo arenoso com cimento e fibras de polipropileno; para o solo sem fibras calcularam um valor para de 0,10 e para o solo reforçado com as fibras encontraram um valor de $=0,15$ usando uma relação de. Outros autores como ANGGRAINI et al. [46] determinaram uma relação direta de $=0,16$ para um solo mole reforçado com fibras de coco e tratado com cal.

Para CORREIA et al. [47] existe uma diminuição na relação $\mathrm{q}_{t} / \mathrm{q}_{\mathrm{u}}(\mathrm{de} 0,20$ para 0,24$)$ com o incremento das quantidades de cimento-escória de alto forno-fibra em uma mesma mistura. Finalmente, MUNTOHAR et al. [48] estudaram a relação $\mathrm{q}_{\mathrm{t}} / \mathrm{q}_{\mathrm{u}}$ para um solo estabilizado com cal e reforçado com fibras. A adição de fibras ao solo estabilizado aumentou ligeiramente o valor de $\xi$ de cerca de 0,11 para 0,13, aumentando o teor de fibra de 0,1 para 1,2\%. Para solos da Formação Guabirotuba, BALDOVINO et al. [17] encontrou para um silte sedimentar estabilizado com cal valores de entre 0,17 e 0,20 com o uso da relação $\eta / L_{\text {iv }}$ e de forma direta $q_{t}=0,2698 q_{u}-59,31$; BALDOVINO et al. [5] calculou valores de $q_{t} /$ $\mathrm{q}_{\mathrm{u}}=0,16$ para misturas solo-cal hidratada independente do tempo de cura. Assim, nota-se que a relação de resistência $\xi$ para solos cimentados/reforçados varia em média entre 10 e $20 \%$. Por conseguinte, as relações empíricas de $\mathrm{q}_{t}$ e $\mathrm{q}_{\mathrm{u}}$ reportadas neste estudo estão dentre dessas faixas.



Figura 12: Relação empírica direta entre compressão simples e tração por compressão diametral para todos os tempos de cura estudados

\section{CONCLUSÕES}

A adição de cinza de celulose e cal no silte amarelo da FG significou um aumento na resistência à compressão simples e à tração por compressão diametral até uma porcentagem de $15 \%$ de cinza acompanhado de $5 \%$ de cal. A melhor maneira de representar esse aumento foi através de uma tendência linear. Os fatores que também influenciaram no aumento da resistência foram o peso específico seco aparente de moldagem, o aumento do tempo de cura, a diminuição dos vazios (porosidade) e o teor volumétrico de cal $\left(\mathrm{L}_{\mathrm{iv}}\right)$ em volume. Adicionalmente, a relação porosidade/teor volumétrico de cal $\eta / \mathrm{L}_{\mathrm{iv}}$ mostrou ser um parâmetro e índice eficiente para estudar a evolução de $\mathrm{q}_{\mathrm{u}}$ e $\mathrm{q}_{\mathrm{t}}$ das misturas solo-cinza-cal. Para melhorar a tendência dos pontos experimentais, $\eta / L_{\text {iv }}$ teve que ajustar-se a um expoente de 1,00 e $-0,50$. Assim, foi possível calcular uma equação de dosagem para $\mathrm{q}_{\mathrm{u}}$ e $\mathrm{q}_{\mathrm{t}}$ do silte estabilizado obtendo ajustes de $99 \%$. Adicionalmente, em termos de acréscimos de resistência, o silte amarelo obteve maiores resistências à tração e à compressão simples para porcentagens de $15 \%$ de cinza e 90-d de cura. Assim, com a relação $\eta / L_{\text {iv }}$ foi possível estabelecer uma relação entre $q_{u}$ e $q_{t}\left(q_{t} / q_{u}\right)$ para as misturas dependendo do tempo de cura, sendo essa relação de $\mathrm{q}_{\mathrm{t}} / \mathrm{q}_{\mathrm{u}}=0,12,0,14$ e 0,16 para 14-d, 28-d e 90-d dias, respectivamente. E, sem a relação $\eta / L_{\text {iv }}$, a constante encontrada foi $\mathrm{q}_{\mathrm{t}}=0,0115 \mathrm{q}_{\mathrm{u}}^{1,38}$.

Os ensaios de CBR também mostraram um aumento na capacidade de carga das misturas solo-cinza de celulose-cal 
quando adicionado $15 \%$ de cinza e $5 \%$ de cal onde se obteve o maior CBR de $8,52 \%$. Assim, de acordo com as normas brasileiras, as misturas de solo-cal com adição de cinza de celulose podem ser empregadas como reforco do subleito na pavimentação, já que seu valor de CBR foi maior ao do solo e menor a 20\%. Por outro lado, considerando os valores de $\mathrm{q}_{\mathrm{u}}$ em 90 -d de cura, a mistura com $15 \%$ de cinza alcançou $1200 \mathrm{kPa}$. Comparando este valor com solo-cal e solo-cimento foi possível estabelecer que o consumo de altas porcentagens de cal e cimento podem ser diminuidas com a adição de $15 \%$ de cinza de celulose, indicando qye pode ser usada potencialmente como material para sub-base. Finalmente, o ensaio de microscopia e microanálisis mostrou que as misturas solo-cinza-cal apresentam uma porosidade significativa e que houve uma interação química entre os materiais.

\section{AGRADECIMENTOS}

Os autores agradecem o apoio financeiro da Fundação Araucária do Paraná, da CAPES e do CNPq-Brasil. Os autores também gostariam de agradecer os comentários, sugestões e correções feitos pelos revisores anônimos que melhoraram o artigo.

\section{REFERÊNCIAS}

[1] MOREIRA, E.B., BALDOVINO, J.J.A., IZZO, R., et al. "Impact of Sustainable Granular Materials on the Behavior Sedimentary Silt for Road Application.” Geotechnical and Geological Engineering, v. 38, n. 1, pp. 917-933.

[2] BALDOVINO, J.J.A., MOREIRA, E.B., CARAZZAI, É., et al. "Equations controlling the strength of sedimentary silty soil-cement blends: influence of voids/cement ratio and types of cement." Int J Geotech Eng, pp. 1-14, 2019.

[3] ARULRAJAH, A., MOHAMMADINIA, A., PHUMMIPHAN, I., et al."Stabilization of Recycled Demolition Aggregates by Geopolymers comprising Calcium Carbide Residue, Fly Ash and Slag precursors." Constr Build Mater, n. 114, pp. 864-73, 2016.

[4] GUPTA, C., PRASAD, A. "Strength and Durability of Lime-Treated Jarosite Waste Exposed to Freeze and Thaw." J Cold Reg Eng 32, 4017025, 2018.

[5] BALdOVINO, J.A., MOREIRA, E.B., IZZO, R., et al."Empirical Relationships with Unconfined Compressive Strength and Split Tensile Strength for the Long Term of a Lime-Treated Silty Soil.” J Mater Civ Eng n. 30, 6018008, 2018.

[6] PUPPALA, A.J. “Advances in ground modification with chemical additives: From theory to practice.” Transp Geotech, n. 9, pp. 123-38, 2016.

[7] PHUMMIPHAN, I., HORPIBULSUK, S., RACHAN, R., et al."High calcium fly ash geopolymer stabilized lateritic soil and granulated blast furnace slag blends as a pavement base material." J Hazard Mater, n. 341, pp. 257-67, 2018.

[8] ARULRAJAH, A., KUA T-A., PHETCHUAY, C., et al. "Spent Coffee Grounds-Fly Ash Geopolymer Used as an Embankment Structural Fill Material.” J Mater Civ Eng, n. 28, 4015197, 2016.

[9] LEANDRO, R.P. "Estudo Laboratorial Acerca Da Possibilidade De Aproveitamento Da Cinza Pesada De Termelétrica Em Bases E Sub-Bases De Pavimentos Flexíveis.” Universidade de São Paulo, Dissertação de Mestrado, 2005.

[10] KORMANN, A.C. “Comportamento geomecânico da Formação Guabirotuba: estudos de campo e laboratório.” Universidade de São Paulo. Tese de Doutorado. doi:10.11606/T.3.2002.tde-20072009-092526, 2002.

[11] SALAMUNI, E., EBERT, H.D., DA SILVA BORGES, M., et al."Tectonics and sedimentation in the Curitiba Basin, south of Brazil." J South Am Earth Sci, v. 15, n. 8, pp. 901-910, 2003.

[12] SALAMUNI, E. "Banco de dados geológicos geo-referenciados da Bacia Sedimentar de Curitiba (PR) como base de sistema de informação geográfica (SIG).” Boletim Paranaense de Geociências, v. 49, 2001.

[13] FELIPE, R. “Características Geológico-Geotécnicas na Formação Guabirotuba.” Mineropar, Curitiba, 2011.

[14] CHAMECKI, P. R. "Sítio Experimental de Geotecnia da UFPR-Objetivos e dados preliminares." In: Anais 1998 ABMS XI Congresso Brasileiro de Mecânica dos Solos e Engenharia Geotécnica. 1998.

[15] BEHAK, L., PERES, W. “Caracterización de un material compuesto por suelo arenoso, ceniza de cáscara de arroz y cal potencialmente útil para su uso en pavimentación.” Revista ingeniería de construcción, v. 23, n. 1, p. 34-41, 2008.

[16] CRISTELO, N.M.C. “Estabilização de solos residuais graníticos através da adição de cal.” Tese de Doutorado. Dissertação (Mestrado em Estruturas, Geotécnica e Fundações)-Universidade do Minho, Braga, 2001.

[17] BALDOVINO, J.A., MOREIRA, E.B., TEIXEIRA, W., et al."Effects of lime addition on geotechnical properties of sedimentary soil in Curitiba, Brazil.” J Rock Mech Geotech Eng, n. 10, pp. 188-94, 2018. 
[18] KARIM, M.E., ALAM, M.J., HOQUE, M.S. "Effect of salinity of water in lime-fly ash treated sand.” Int J Geo-Engineering, n. 8, p. 15, 2017.

[19] CONSOLI, N.C., DA ROCHA, C.G., SILVANI, C. "Devising dosages for soil-fly ash-lime blends based on tensile strength controlling equations." Constr Build Mater, n. 55, pp. 238-45, 2014.

[20] NOLASCO, A. M., GUERRINI, I. A., BENEDETTI, V. "Uso de resíduos urbanos e industriais como fonte de nutrientes e condicionadores de solos florestais." Nutrição e fertilização florestal. Piracicaba: IPEF, p. 385-414, 2000.

[21] MARCON, A.F., CORRÊA, J.F., TRICHÊS, G. "Improvement in Physical and Mechanical Properties of Soils by the Addition of Lime for Paving Roads.” Transp Res Rec J Transp Res Board, n. 2473, pp. 209-14, 2015.

[22] MOREIRA, E.B., BALDOVINO, J.A., ROSE, J.L., et al. "Effects of porosity, dry unit weight, cement content and void/cement ratio on unconfined compressive strength of roof tile waste-silty soil mixtures." J Rock Mech Geotech Eng, n. 11, pp. 369-78, 2019.

[23] BALDOVINO, J., IZZO, R., PEREIRA, M., et al. "Equations controlling tensile and compressive strength ratio of sedimentary soil-cement mixtures under optimal compaction conditions". Journal of Materials in Civil Engineering, v. 32, n. 1, p. 04019320, 2020.

[24] BALDOVINO, J.A., IZZO, R., DA SILVA, E., ROSE, J. "Sustainable use of recycled glass powder in soil stabilization.” [Accepted Full Technical Paper] J Mater Civ Eng, 2020.

[25] BALDOVINO, J.J.A, IZZO, R. Sustainable Use of Recycled-Glass Powder in Soil Stabilization. Journal of Materials in Civil Engineering, v. 32, n. 5, p. 04020080, 2020.

[26] ASTM. ASTM D 2487 - 11 "Standard Practice for Classification of Soils for Engineering Purposes (Unified Soil Classification System).” ASTM Int West Conshohocken, Pa, D5521-5:1-5. doi:10.1520/D2487-11, 2011.

[27] ABNT. NBR 7180 - “Solo - Determinação do limite de plasticidade.” Assossiação Bras Normas Técnicas, 2016.

[28] ABNT. NBR 6459 - “Solo - Determinação do limite de liquidez.” Assossiação Bras Normas Técnicas, 2016.

[29] ASTM. ASTM D 854 - 14 "Standard Test Methods for Specific Gravity of Soil Solids by Water Pycnometer 1.” ASTM Int West Conshohocken, $\mathrm{Pa}, 2014$.

[30] ABNT. NBR 16605 - “Cimento Portland e outros materiais em pó — Determinação da massa específica” Assossiação Bras Normas Técnicas, 2017.

[31] ABNT. NBR 7182 - “Solo - Ensaio de Compactação.” Assossiação Bras Normas Técnicas, 2016.

[32] ABNT. NBR 10004 - “Resíduos sólidos - Classificação” Assossiação Bras Normas Técnicas, 2004.

[33] EADES, J..L, GRIM, R.E. “A quick test to determine lime requirements for lime stabilization. 45th Annu. Meet. Comm.” Lime Lime-Fly Ash Stab., doi:10.1016/j.foodchem.2007.03.029., p. 61-72, 1960.

[34] CIANCIO, D., BECKETT, C.T.S., CARRARO, J.A.H. "Optimum lime content identification for lime-stabilised rammed earth.” Constr Build Mater, n. 53, pp. 59-65, 2014.

[35] RIOS, S., VIANA DA FONSECA, A., BAUDET, B.A. "Effect of the Porosity/Cement Ratio on the Compression of Cemented Soil.” J Geotech Geoenvironmental Eng, n. 138, pp. 1422-6, 2012.

[36] FESTUGATO, L., MENGER, E., BENEZRA, F., et al."Fibre-reinforced cemented soils compressive and tensile strength assessment as a function of filament length.” Geotext Geomembranes, n. 45, pp. 77-82, 2017.

[37] CONSOLI, N.C., PRIETTO, P.D.M., DA SILVA LOPES, L., et al.“Control factors for the long term compressive strength of lime treated sandy clay soil.” Transp Geotech, n. 1, pp. 129-36, 2014.

[38] ABNT. NBR 9895- “Solo - Índice de suporte Califórnia (ISC) - Método de ensaio.” Assossiação Bras Normas Técnicas, 2017.

[39] ABNT. NBR 5739 - “Concreto - Ensaios de Compressão de Corpos de Prova Cilíndricos.” Assoc Bras Normas Técnicas, 2007.

[40] ABNT. NBR 7222- "Concreto e argamassa — Determinação da resistência à tração por compressão diametral de corpos de prova cilíndricos.” Assoc Bras Normas Técnicas, 2011.

[41] MENDOZA, C., CAICEDO, B. "Elastoplastic framework of relationships between CBR and Young's modulus for granular material.” Road Mater Pavement Des, doi:10.1080/14680629.2017.1347517. n. 19, pp. 1796-815, .

[42] DNIT. Manual de Pavimentação. Dep Nac Infraestrutura Transp. doi:IPR - 719., p. 274, 2006. 
[43] Texas Department of Transportation. (TxDOT) test procedure for soil-cement testing. Tex-120-E, Austin, TX, 2013.

[44] DIAMBRA, A., FESTUGATO, L., IBRAIM, E., et al."Modelling tensile/compressive strength ratio of artificially cemented clean sand.” Soils Found, n. 58, pp. 199-211, 2018.

[45] CONSOLI, N.C., QUIÑÓNEZ, R.A., GONZÁLEZ, L.E., et al."Influence of Molding Moisture Content and Porosity/ Cement Index on Stiffness, Strength, and Failure Envelopes of Artificially Cemented Fine-Grained Soils." J Mater Civ Eng, n. 29, 4016277, 2017.

[46] ANGGRAINI, V., ASADI, A., HUAT, B.B.K., et al."Effects of coir fibers on tensile and compressive strength of lime treated soft soil." Measurement, n. 59, pp. 372-81, 2015.

[47] CORREIA, A.A.S., VENDA OLIVEIRA, P.J., CUSTÓDIO, D.G. "Effect of polypropylene fibres on the compressive and tensile strength of a soft soil, artificially stabilised with binders." Geotext Geomembranes, n. 43, pp. 97-106, 2015.

[48] MUNTOHAR, A.S., WIDIANTI, A., HARTONO, E., et al."Engineering Properties of Silty Soil Stabilized with Lime and Rice Husk Ash and Reinforced with Waste Plastic Fiber.” J Mater Civ Eng, n. 25, pp. 1260-70, 2013.

\section{ORCID}

Ronaldo Luis dos Santos Izzo Jair de Jesus Arrieta Baldovino Alexandre Erbs Danilo Lima

Ölaf Graupmann https://orcid.org/0000-0002-6290-1520

https://orcid.org/0000-0001-7740-1679

https://orcid.org/0000-0002-6316-8148

https://orcid.org/0000-0002-0040-3358

https://orcid.org/0000-0003-2227-1437 